\title{
Fracture experience of patients with coeliac disease: a population based survey
}

\author{
K Thomason, J West, R F A Logan, C Coupland, G K T Holmes
}

Gut 2003;52:518-522

See end of article for authors' affiliations

\section{Correspondence to:}

Professor R Logan, Division of Epidemiology and Public Health, University Hospital, Queen's Medical Centre, Nottingham NG7 2UH, UK; richard.logan@ nottingham.ac.uk

Accepted for publication 29 October 2002

\begin{abstract}
Background: While coeliac disease is now recognised as being associated with both osteoporosis and osteomalacia, the size of any increase in the risk of fracture in patients with coeliac disease compared with the general population has not been quantified.

Aim: To examine the fracture experience of adults with coeliac disease compared with the general population.

Subjects: Patients with coeliac disease diagnosed in adulthood and born before 1950, selected from two large population based disease registers, and age and sex frequency matched controls identified from local general practitioner lists.

Methods: A four page lifestyle and general health questionnaire which included specific questions about fracture experience.

Results: Analysis was performed on 244 patients with coeliac disease and 161 controls, giving response rates of $89 \%$ and $72 \%$, respectively. Eighty two $(35 \%)$ coeliac patients and $53(33 \%)$ controls reported ever having sustained one or more fractures, giving an age and sex adjusted odds ratio of 1.05 (95\% confidence interval (Cl) 0.68-1.62). The most common fracture site reported was the forearm or wrist, with an adjusted odds ratio of $1.21(95 \% \mathrm{Cl} 0.66-2.25)$ for patients with coeliac disease having had a forearm or wrist fracture. Low trauma fractures were reported by 37 patients with coeliac disease $(15.7 \%)$ and by 21 controls $(13.8 \%)$, with an adjusted odds ratio of $1.16(95 \% \mathrm{Cl} 0.65-2.10)$. The risk of low trauma fracture was slightly higher in coeliac men than women (odds ratio 1.28 compared with 1.12), but this difference was not statistically significant $(p=0.84)$. After adjustment for age, sex, body mass index, and smoking status, patients with coeliac disease reported $13 \%$ more low trauma fractures than controls (odds ratio $1.13,95 \% \mathrm{Cl} 0.60-2.12$ ). There was no difference in low trauma fracture risk before and after diagnosis of coeliac disease.

Conclusion: No overall increased fracture risk in patients with coeliac disease was observed. Although severe osteoporosis may develop in a subset of patients, as a whole patients with coeliac disease do not represent a population at particularly high risk of osteoporotic fracture and thus targeting them for osteoporosis screening and treatment is not justified.
\end{abstract} actual fracture risk in patients with coeliac disease. ${ }^{10-12}$ In addition, the predictive value of bone densitometry is not sufficient to accurately identify individuals who will sustain fractures. ${ }^{813}$ The aim of this study was to establish the size of any increased fracture risk in adult coeliac disease.

\section{METHODS}

\section{Patients with coeliac disease}

Patients were selected from two large population based coeliac disease registers, compiled within secondary care institutions. Both registers are held in Access databases. Patients on the registers were identified from searching the computer held histopathology records and local gastroenterologists. The Nottingham register has been maintained in the Division of Public Health and Epidemiology at Queen's Medical Centre. The Derby register has been maintained by GKTH in the Gastroenterology Department at the Derbyshire Royal Infirmary. The Derby register has been prospectively collected since 1978. At the time of selection there were over 400 subjects with coeliac disease on each register. Patients included on both registers had a diagnosis based on a combination of compatible clinical picture, abnormal intestinal mucosa (ranging from severe partial villous atrophy to subtotal villous atrophy), and coeliac disease related serology. Date of diagnosis was defined as date of first abnormal duodenal or jejunal biopsy. Less than $7 \%$ of patients with coeliac disease did not have a duodenal biopsy and in a few subjects the date of diagnosis preceded the date of the first abnormal biopsy by several

Abbreviations: HRT, hormone replacement therapy; BMI, body mass index; IBD, inflammatory bowel disease. 
Table 1 Characteristics of patients with coeliac disease and controls

\begin{tabular}{|c|c|c|c|}
\hline \multirow{2}{*}{$\begin{array}{l}\text { Variable } \\
\text { Male }\end{array}$} & $\begin{array}{l}\text { Patients with coeliac } \\
\text { disease }(n=244)\end{array}$ & Controls $(n=161)$ & \multirow{2}{*}{$\begin{array}{c}\mathrm{p} \text { Value } \\
0.86^{*}\end{array}$} \\
\hline & $73 \quad(29.9 \%)$ & $46 \quad(28.6 \%)$ & \\
\hline Female & $171 \quad(70.1 \%)$ & 115 (71.4\%) & \\
\hline Age (y) (mean, SD) & $60.2(10.1)$ & $61.2(10.1)$ & $0.34 \ddagger$ \\
\hline \multicolumn{4}{|l|}{ Age group (y) } \\
\hline$<55$ & $(38.1 \%)$ & (31.9\%) & $0.30 t$ \\
\hline $55-64$ & $(27.5 \%)$ & $(33.1 \%)$ & \\
\hline $65-74$ & $(26.2 \%)$ & $(23.1 \%)$ & \\
\hline $75+$ & $20 \quad(8.2 \%)$ & $19 \quad(11.9 \%)$ & \\
\hline Body mass index (median, IQ range) & $23.9(21.7-25.7)$ & $25.8(23.3-29.1)$ & $<0.0019$ \\
\hline \multicolumn{4}{|l|}{ Smoking: } \\
\hline Never smoked & $(52.5 \%)$ & $(43.3 \%)$ & $0.012 t$ \\
\hline Ex-smoker & $(33.1 \%)$ & $(31.8 \%)$ & \\
\hline Current smoker & $34 \quad(14.4 \%)$ & $39 \quad(24.8 \%)$ & \\
\hline Maximum smoked (median, $I Q$ range) & $15.0(10.0-20.0)$ & $20.4(12.8-25.0)$ & 0.0089 \\
\hline Diagnosis of osteoporosis & $18(7.4 \%)$ & $5(3.1 \%)$ & $0.11^{*}$ \\
\hline Age at menarche (y) (median, IQ range) & $(12-15)$ & $(12-15)$ & 0.199 \\
\hline Age at menopause (y) (median, $I Q$ range) & $(42-51)$ & $(44-51)$ & $0.36 \pi$ \\
\hline \multicolumn{4}{|c|}{$\begin{array}{l}\text { * } \chi^{2} \text { test. } \\
+\chi^{2} \text { test for trend. } \\
\text { fUnpaired } t \text { test. } \\
\text { IMann-Whitney U test. } \\
\text { Data were missing on body mass index for } 10 \text { coeliacs and seven controls, on age at menarche for eight } \\
\text { coeliacs and nine controls, on age at menopause for nine coeliacs and nine controls, on smoking status for } \\
\text { eight coeliacs and four controls, and on age for one control. }\end{array}$} \\
\hline
\end{tabular}

years. Any patient in whom a diagnosis was made before the age of 16 years was excluded. As the intention was to assess fractures in which osteoporosis was likely to be important, only patients with coeliac disease born before 1950 were included.

\section{Control group}

Control subjects were selected from the Nottingham Family Health Services Authority database of people registered with a general practitioner, using an age and sex stratified random sample to obtain frequency matching with patients with coeliac disease.

\section{Questionnaire}

A four page questionnaire was mailed to 274 patients with coeliac disease and 224 control subjects. After four weeks a second questionnaire was sent to non-responders. Information was collected on potential confounding variables including physical activity at work and leisure time, past medical history and regular medication, alcohol intake, smoking behaviour, height, weight, and occupation. Specific questions were asked regarding reproductive history, hormonal status, and current and previous use of hormone replacement therapy (HRT) in women, and compliance with a gluten free diet in patients with coeliac disease. Participants were asked whether they had ever broken a bone. In case of fractures, participants were asked to describe in brief, which bone(s) had fractured, what had caused each individual fracture (for example, a fall from a height, road traffic accident, etc), and their age when the fracture occurred. Participants were also asked to tick a box to describe which bone(s) had been fractured. Based on the participants' accounts of the fractures, fractures were categorised into low and non-low trauma fractures. The categorisation was based on the definition of low trauma fracture as a fracture caused by a fall from a standing height or less, on the same level. Fractures occurring from an impact of any other mode were classified as non-low trauma. This categorisation was performed blinded to case or control status by a single investigator (JW).

We estimated that to detect a twofold or greater increase in the risk of fracture with $90 \%$ power and using a two sided significance level of 0.05 would require data from 200 patients with coeliac disease and 200 controls, assuming one third of controls reported having had at least one fracture. With data from 244 patients with coeliac disease and 161 controls, the power to detect a twofold increase in fracture risk was $89 \%$. The local research ethics committees of the Nottingham and Derby hospitals approved the study.

\section{Analysis}

Unconditional logistic regression was performed to estimate the odds ratios for fracture occurrence associated with coeliac disease status, using SPSS. Odds ratios and $95 \%$ confidence intervals (CI) were calculated, adjusted for sex and age group. A further analysis also adjusted for potential confounding effects of body mass index (BMI) and smoking status. Where numbers were small for specific fracture sites, an exact stratified analysis was performed to calculate odds ratios and 95\% CI using Egret. To compare low trauma fracture incidence between patients with coeliac disease and controls at equivalent ages before and after coeliac disease diagnosis, a Cox's proportional hazards model was fitted. Only the first low trauma fracture was included. In the comparison of rates before diagnosis, patients with coeliac disease were censored at their age of diagnosis, and low trauma fractures occurring at or after this age were excluded. Controls were censored at their current age if they had not reported a low trauma fracture. In the comparison of rates after diagnosis, patients with coeliac disease were entered into the analysis at their age of diagnosis, and low trauma fracture occurring before this age were excluded. The assumptions of the proportional hazards models were checked using log-minus-log plots, and by incorporating time dependent terms. These analyses were performed using Egret.

\section{RESULTS}

A total of 244 patients with coeliac disease and 161 controls returned their questionnaire, giving response rates of $89 \%$ and $72 \%$, respectively. Table 1 shows descriptive statistics for the baseline characteristics of the two groups of respondents. Patients with coeliac disease had a statistically significant lower BMI than controls and were less likely to report ever having smoked. Among those who reported having ever smoked, the maximum amount smoked by patients with coeliac disease was significantly less than by controls. 
Table 2 Medication use reported by patients with coeliac disease and controls

\begin{tabular}{|c|c|c|c|c|}
\hline Medication & $\begin{array}{l}\text { Patients with coeliac } \\
\text { disease }(\mathrm{n}(\%))\end{array}$ & $\begin{array}{l}\text { Controls } \\
\text { (n (\%)) }\end{array}$ & Odds ratio & $95 \% \mathrm{Cl} \dagger$ \\
\hline Prescribed medication for $>3 / 12$ in past year & $152(63.6)$ & $81(50.9)$ & 1.92 & $1.24-2.98$ \\
\hline Folic acid & $42(18.2)$ & $1(0.7)$ & $31.55^{*}$ & $5.19-1294.78$ \\
\hline Iron & $32(14.1)$ & $0(0.0)$ & $\operatorname{lnf} *$ & 5.85 -inf \\
\hline Calcium & $10(4.4)$ & $0(0.0)$ & $\operatorname{lnf} *$ & 1.45 -inf \\
\hline Diabetes drugs & $15(6.6)$ & $2(1.4)$ & $1.76 *$ & $0.66-5.25$ \\
\hline Thyroxine & $26(11.6)$ & $8(5.7)$ & $2.28 *$ & $0.94-6.10$ \\
\hline Drugs for heart disease & 25 (11.0) & $26(17.8)$ & $0.62 *$ & $0.32-1.18$ \\
\hline Antihypertensive drugs & $20(8.8)$ & $28(19.4)$ & $0.40 *$ & $0.20-0.77$ \\
\hline Steroid use (ever) & $35(15.5)$ & $18(12.4)$ & $1.29 *$ & $0.68-2.52$ \\
\hline \multicolumn{5}{|l|}{ Females only } \\
\hline HRT (ever) $\ddagger$ & $43(31.2)$ & $21(21.2)$ & 1.98 & $1.00-3.90$ \\
\hline \multicolumn{5}{|l|}{ Duration of HRT } \\
\hline$<1$ year & $6(4.4)$ & $5(5.1)$ & 1.28 & $0.38-4.51$ \\
\hline 1 yeart & $36(26.3)$ & 15 (15.3) & 2.51 & $1.18-5.32$ \\
\hline
\end{tabular}

*Exact analysis.

†Adjusted for age group $(<55,55-64,65-74,>74)$ and sex.

¥Hormone replacement therapy (HRT) values are for postmenopausal women only. Information was missing for some subjects, including 10 women on HRT, and \% exclude these subjects.

Table 3 Fractures reported by patients with coeliac disease and controls

\begin{tabular}{|c|c|c|c|c|}
\hline Fracture type & $\begin{array}{l}\text { Patients with } \\
\text { coeliac disease } \\
\text { (n \%) } \ddagger\end{array}$ & $\begin{array}{l}\text { Controls } \\
\text { (n (\%)) } \ddagger\end{array}$ & Odds ratiof & $95 \% \mathrm{Cl} \dagger$ \\
\hline Any fracture & 82 (34.5) & $53(33.3)$ & 1.05 & $0.68-1.62$ \\
\hline Hip & $2(0.8)$ & $2(1.3)$ & $0.66 *$ & $0.05-9.50 *$ \\
\hline Forearm/wrist & 39 (16.4) & $22(13.8)$ & 1.21 * & $0.66-2.25^{*}$ \\
\hline Humerus & $9(3.8)$ & $1(0.6)$ & $6.99 *$ & $0.95-309.29$ * \\
\hline Hand/finger & 12 (5.0) & 13 (8.2) & $0.53^{*}$ & $0.21-1.34^{*}$ \\
\hline Clavicle & $10(4.2)$ & 6 (3.8) & $1.08 *$ & $0.34-3.73^{*}$ \\
\hline Ankle, foot, or toe & 29 (12.2) & $18(11.3)$ & $1.10^{*}$ & $0.56-2.21$ * \\
\hline Femur & $6(2.5)$ & $2(1.3)$ & $1.96^{*}$ & $0.34-20.20$ * \\
\hline Lower leg & $10(4.2)$ & $8(5.0)$ & $0.85^{*}$ & $0.29-2.55^{*}$ \\
\hline Other site & $6(2.5)$ & $4(2.5)$ & $1.04^{*}$ & $0.24-5.08^{*}$ \\
\hline Low trauma fracture & 37 (15.7) & $21(13.8)$ & 1.16 & $0.65-2.10$ \\
\hline In men & 8 (11.0) & $4(9.3)$ & 1.28 & $0.36-4.66$ \\
\hline In women & 29 (17.3) & $17(15.6)$ & 1.12 & $0.58-2.19$ \\
\hline
\end{tabular}

Table 2 shows the reported medication use of respondents. Although patients with coeliac disease reported statistically significant greater use of folic acid, iron, and calcium supplements, only $4 \%$ reported taking calcium. In contrast, patients with coeliac disease reported significantly less use of hypotensive drugs and drugs for heart disease. More women with coeliac disease $(31 \%)$ reported having ever used HRT than controls $(21 \%)$ and more had used HRT for greater than one year than controls, both differences being significant at the 5\% level.

\section{Fracture risk}

Eighty two (34.5\%) patients with coeliac disease and 53 (33.3\%) controls reported ever having sustained one or more fractures, giving an odds ratio of 1.05 (95\% CI 0.68-1.62) after adjustment for age group and sex (table 3 ). The most common fracture site reported was the forearm or wrist with an adjusted odds ratio of 1.21 (95\% CI 0.66-2.25). Although there were increases in the risk of fractures of certain bones such as the humerus, none of the increases was significant at the 5\% level.

Low trauma fractures were reported by 37 patients with coeliac disease $(15.7 \%)$ and 21 controls $(13.8 \%)$, giving an age adjusted odds ratio of 1.16 (95\% CI $0.65-2.10)$. Having sustained two or more low trauma fractures was reported by nine $(3.7 \%)$ patients with coeliac disease compared with three ( $1.9 \%)$ controls, giving an adjusted odds ratio of 2.09 (95\% CI 0.55-7.94). The risk of low trauma fracture was slightly higher in men than women (odds ratio 1.28 compared with 1.12 ) but this difference was not statistically significant $(p=0.91)$. After adjustment for age group, sex, BMI, and smoking status, patients with coeliac disease had a 13\% greater risk of low trauma fractures than controls (odds ratio $1.13,95 \%$ CI $0.60-$ 2.12 ), and adding HRT use to the model increased the risk in women with coeliac disease to $18 \%$ (odds ratio $1.18,95 \%$ CI $0.58-2.43)$.

\section{Effect of diagnosis of coeliac disease on fracture risk}

Of the 37 patients with coeliac disease reporting low trauma fractures, 20 experienced their first low trauma fracture before diagnosis of their coeliac disease and 10 patients sustained their first low trauma fracture after diagnosis. For two patients their reported age when their first low trauma fracture occurred was the same as their age at coeliac disease diagnosis while the remaining five patients with coeliac disease were unsure when the low trauma fracture had occurred. Using a Cox proportional hazards model to estimate the hazard ratio for low trauma fractures occurring before diagnosis of coeliac disease gave a hazard ratio of 1.24 (95\% CI 0.65-2.39) for risk of low trauma fracture in patients with coeliac disease relative 
to the risk in controls at the equivalent age, adjusted for age group and sex. For low trauma fracture incidence after diagnosis of coeliac disease, the hazard ratio was 1.33 (95\% CI $0.63-2.81$ ), adjusted for age group and sex.

\section{DISCUSSION}

In this survey of patients with coeliac disease, we found only small and statistically non- significant increases in their bone fracture risk or in their risk of "low trauma" fractures compared with the general population. In particular, fractures of the hip and forearm were reported with a similar frequency in patients with coeliac disease and controls. We did find a greater increase in the risk of "low trauma" fracture in men with coeliac disease (odds ratio $1.28,95 \%$ CI $0.36-4.60$ ) but this finding was based on small numbers and again was not statistically significant. Only minor changes were seen in the risk estimates when the results were adjusted for confounding factors. There was no significant change in fracture risk after diagnosis of coeliac disease. These results suggest that the concerns about fracture risk in patients with coeliac disease have been exaggerated.

There were two major differences between patients with coeliac disease and controls. Firstly, BMI was lower in patients although the mean value was within the normal range (20-25 $\mathrm{kg} / \mathrm{m}^{2}$ ), and secondly, patients with coeliac disease were less likely to have smoked. The first finding is probably a consequence of having coeliac disease. The second finding has been discussed in detail elsewhere. ${ }^{14}$ Interestingly, significantly fewer patients with coeliac disease reported use of medications for hypertension and heart disease than controls and more reported ever taking HRT than controls.

Our study represents the largest survey of the fracture experience of patients with coeliac disease, yet we appreciate that there may be potential limitations. While the questionnaire response from patients with coeliac disease was high $(89 \%)$ the response rate of controls was only $72 \%$. This could result in a response bias if non-responders were more likely to have never had a fracture. We have no reason to believe that this is the case; to conceal its intention, the questions on fracture experience were placed in the middle of the questionnaire. In addition, if all non-responding controls had responded and reported no fractures, the prevalence in the control group would still be $24 \%$. Although we were reliant on self reporting of fractures, others have found self report to be an accurate means of obtaining information about past major fractures. ${ }^{15}$ We used a similar study design to Vestergaard et al who studied fracture risk in inflammatory bowel disease (IBD) and found that only $6 \%$ of reported fractures could not be substantiated and that in those not reporting fractures no fractures were found. ${ }^{16}$ False positive fracture reports tend to be for small fractures and it is possible that we have slightly overestimated fracture prevalence in those surveyed. None the less, there is no reason to believe that false positive reports of fractures in our study would differ between patients with coeliac disease and controls. There may also be under reporting of some other fractures, particularly rib and vertebral fractures. However, we have no reason to believe that this would be selective. Women with coeliac disease did report using HRT more than controls (table 2) and this may have reduced the number of fractures they experienced. However, in our analysis, adjustment for HRT use resulted in little change in the risk estimates.

Our findings of only small increases in fracture risk can be compared with those found in IBD where similar increases in bone loss rates and decreases in bone mineral density have been demonstrated. Fracture risk in IBD appears to be of the same order of magnitude as in our study. For example, in a database study of 6027 IBD patients in Canada, fracture risk was moderately increased (relative risk 1.41, CI 1.27-1.56). ${ }^{17}$ Vestergaard et al found an increased risk of fracture in Crohn's disease (relative risk 1.7, 95\% CI 1.2-2.3) but the increase was only evident in women and not in men with Crohn's disease or in men or women with ulcerative colitis. Loftus et al in two recent studies from Olmsted County were unable to show any increases in fracture risks for either Crohn's disease or ulcerative colitis. ${ }^{16} 1819$

Coeliac disease is generally a less severe illness than IBD and patients are rarely exposed to systemic corticosteroids as a treatment for their disease. In addition, most patients with coeliac disease have some increase in their bone density following initiation of treatment and in treated coeliacs subsequent bone loss is no greater than would be expected in the general population..$^{20-23}$ It seems unlikely therefore that patients with coeliac disease would have far greater fracture risks than patients with IBD.

Our results are in contrast with the findings of three similar studies of the fracture experience of coeliac disease patients. In the first, Vasquez et al compared the fracture experience of 165 patients (median age of 40 years) with that of controls with functional gastrointestinal disorders and found a threefold increase in fracture risk (odds ratio 3.5, 95\% CI 1.8-7.2) based on $25 \%$ of patients reporting fractures and only $8 \%$ of controls. ${ }^{10}$ It is notable that the mean BMI of their patients (21.4) was much lower than in our study and that the median duration of symptoms prior to diagnosis was over 10 years, suggesting that in terms of severity their patients represent the tip of the coeliac disease iceberg. Only $7 \%$ of their patients experienced fractures after starting a gluten free diet and although they found reductions in mean bone mineral density $\mathrm{z}$ scores of greater than one standard deviation, there was no relationship between score and fracture experience. A subsequent study from the same group, as yet published only as an abstract, found that the increase in fracture experience was confined to their patients with coeliac disease presenting with "classical malabsorption". ${ }^{24}$ In the third study, Fickling et al reported a "relative risk" of fracture of 7 based on a survey of 75 patients with a mean age of 52 years and age and sex matched controls selected from patients who had attended for bone densitometry. ${ }^{11}$ While $21 \%$ of their coeliac disease patients reported a past fracture, only two (3\%) of the controls did.

Allowing for age and sex differences, the proportions of patients with coeliac disease reporting fractures in these three studies are not greatly different from ours. Differences in the estimates of risk are mainly attributable to the fracture experience reported by the different control groups. Our controls were selected from the general population, as represented by general practitioner lists (greater than $98 \%$ of the UK population are believed to register with a general practitioner) and we believe their fracture experience is representative. In support of this, fracture incidence in adults in the UK has been found to be approximately 50-100/10 000/year, suggesting that by age 50 years the numbers reporting a previous fracture will be at least $25 \%$ of the population..$^{25}$

Thus it seems likely that any increase in fracture risk in diagnosed coeliac disease is much smaller than previously suggested. In support of this a recent prospective Danish study was unable to detect any increase in fracture risk in 1021 patients with a mean 14 years of follow up. ${ }^{26}$ Nevertheless, findings such a small increased risk require explanation as patients with coeliac disease undoubtedly have an increased risk of osteoporosis. ${ }^{2-7}$ The reasons for this apparent paradox are probably due to the complex interplay of other risk factors for fracture and bone mineral density. ${ }^{27}{ }^{28}$ For example, risk of falling, selective use of HRT and/or other drugs that influence fracture risk are likely to be contributory factors.

\section{CONCLUSION}

Although this is the largest survey of fractures in coeliac disease so far performed, we have demonstrated only small and 
statistically non-significant increases in fracture risk. Larger studies are clearly needed to more precisely define risks and particularly to determine whether treated patients have a materially increased risk. Given the increase in osteoporosis evident in some patients with coeliac disease there is likely to be some increase in fracture risk but it probably relates to mainly those with undiagnosed or untreated disease rather than those with treated disease seen in hospital review clinics. Targeting of the latter group for surveillance as suggested by the recent British Society of Gastroenterology guidelines is not yet supported by evidence and represents a poor use of resources.

\section{Authors' affiliations}

K Thomason, J West, R F A Logan, Division of Epidemiology and

Public Health, University of Nottingham, UK

C Coupland, Division of Primary Care, University of Nottingham, UK

G K T Holmes, Derby Royal Infirmary, Derby, UK

\section{REFERENCES}

1 Cooke WT, Holmes GK. Coeliac Disease. New York: Churchill Livingstone, 1984.

2 Kemppainen $\mathrm{T}$, Kroger $\mathrm{H}$, Janatuinen $\mathrm{E}$, et al. Osteoporosis in adult patients with celiac disease. Bone 1999:24:249-55

3 Pistorius LR, Sweidan WH, Purdie DW, et al. Coeliac disease and bone mineral density in adult female patients. Gut 1995;37:639-42.

4 Valdimarsson T, Toss G, Ross I, et al. Bone mineral density in coeliac disease. Scand J Gastroenterol 1994;29:457-61.

5 Gonzalez, D, Mazure R, Mautalen C, et al. Body composition and bone mineral density in untreated and treated patients with celiac disease. Bone1995; 16:231-4.

6 Meyer D, Stavropolous S, Diamond B, et al. Osteoporosis in a North American adult population with celiac disease. Am J Gastroenterol 2001;96:112-19.

7 Walters JR. Bone mineral density in coeliac disease. Gut1994;35:1501.

8 Marshall D, Johnell O, Wedel H. Meta-analysis of how well measures of bone mineral density predict occurrence of osteoporotic fracture. BM 1996; 312:1254-9

9 Scott EM, Gaywood I, Scott BB. Guidelines for osteoporosis in coeliac disease and inflammatory bowel disease. Gut 2000;46(suppl 1):1-8.

10 Vasquez H, Mazure R, Gonzalez D, et al. Risk of fractures in celiac disease patients: a cross-sectional, case-control study. Am J Gastroenterol 2000;95: 183-9.
11 Fickling WE, McFarlane XA, Bhalla AK, et al. The clinical impact of metabolic bone disease in coeliac disease. Postgrad Med J 2001;77:33-6.

12 Fickling WE, Holdoway A, Robertson DA, et al. Prevalence of fragility fracture in coeliac disease and inflammatory bowel disease. Gut 2001:48(suppl 1):A60.

13 van Hemert AM, Vandenbroucke JP, Birkenhager JC, et al. Prediction of osteoporotic fractures in the general population by a fracture risk score. A 9-year follow-up among middle- aged women. Am J Epidemiol 1990;132:123-35

14 Austin A, Logan RFA, Thomason K, et al. Cigarette smoking and adult coeliac disease. Scand J Gastroenterol 2002;37:978-82.

15 Honkanen K, Honkanen R, Heikkinen L, et al. Validity of self-reports of fractures in perimenopausal women. Am J Epidemiol 1999;150:511-16.

16 Vestergaard P, Krogh K, Rejnmark L, et al. Fracture risk is increased in Crohn's disease, but not in ulcerative colitis. Gut 2000;46:176-81.

17 Bernstein CN, Blanchard JF, Leslie W, et al. The incidence of fracture among patients with inflammatory bowel disease. A population-based cohort study. Ann Intern Med 2000; 133:795-9.

18 Loftus EV, Crowson CS, Sandborn WJ, et al. Long term fracture risk in patients with Crohn's disease: a population-based study in Olmsted County, Minnesota. Gastroenterology 2002;123:468-75.

19 Loftus EV, Crowson CS, Sandborn WJ, et al. Risk of fracture and ulcerative colitis: a population-based study in Olmsted County, Minnesota. Gastroenterology 2002;122:A602

20 Kemppainen $\mathbf{T}$, Kroger $\mathrm{H}$, Janatuinen $\mathrm{E}$, et al. Bone recovery after a gluten-free diet: a 5-year follow-up study. Bone 1999:25:355-60.

21 Mautalen C, Gonzalez D, Mazure R, et al. Effect of treatment on bone mass, mineral metabolism, and body composition in untreated celiac disease patients. Am J Gastroenterol 1997;92:313-18.

22 Sategna-Guidetti C, Grosso SB, Grosso S, et al. The effects of 1 -year gluten withdrawal on bone mass, bone metabolism and nutritional status in newly-diagnosed adult coeliac disease patients. Aliment Pharmacol Ther 2000;14:35-43.

23 Valdimarsson T, Lofman O, Toss $G$, et al. Reversal of osteopenia with diet in adult coeliac disease. Gut 1996;38:322-7.

24 Moreno ML, Vasquez H, Mazure RM, et al. The increased prevalence of bone fractures in celiac disease is related with the presence of a classically symptomatic clinical course. Gastroenterology 2002;122:A180

25 van Staa TP, Dennison EM, Leufkens HG, et al. Epidemiology of fractures in England and Wales. Bone 2001;29:517-22.

26 Vestergaard P, Mosekilde L. Fracture risk in patients with celiac disease, Crohn's disease, and ulcerative colitis: a nationwide follow-up study of 16,416 patients in Denmark. Am J Epidemiol 2002;156:1-10.

27 Cummings SR, Melton III J. Epidemiology and outcomes of osteoporotic fractures. Lancet 2002;359:1761-7.

28 Kanis JA. Diagnosis of osteoporosis and assessment of fracture risk. Lancet 2002;359: 1929-36. 